\title{
FUNGSI PENDEKATAN BIMBINGAN DAN KONSELING
}

IRMA

Sekolah Tinggi Agama Islam (STAI) Darul Dakwah Wal-Irsyad (DDI) Kota Makassar, Indonesia

Email: irmhaimmha1234@gmail.com

\begin{abstract}
ABSTRAK
Konseling adalah hubungan pribadi yang dilakukan secara tatap muka antara dua orang dalam mana konselor melalui hubungan itu dengan kemampuan-kemampuan khusus yang dimilikinya, menyediakan situasi belajar. Dalam hal ini konseling dibntu untuk memahami diri sendiri, keadan sekarang, dan kemungkinan keadaannya masa depan yang dapat ia ciptakan dengan menggunakan potensi yang dimilikinya, demi untuk kesejahteraan pribadi maupun masyarakat.
\end{abstract}

Kata Kunci: Fungsi Pendekatan, Bimbingan, Konseling 


\section{PENDAHULUAN}

Pendidikan adalah aset yang paling penting didalam kehidupan bangsa dan bernegara, begitupun dengan berdakwah diera sosial media karena bagaimana pun tidak ada bangsa yang maju tanpa diiringi pendidikan dan dakwah yang bermutu ${ }^{1}{ }^{1}$ Pendidikan yang berkualitas bukan hanya dilihat dari sejauh mana proses pengajarannya, terdapat tiga bidang pendidikan yang harus menjadi perhatian, diantaranya; Bidang administrasi dan Kepemimpinan, Bidang intruksional dan kuliner, dan Bidang pembinaan siswa ( bimbingan dan Konseling).

Dalam makala ini akan membahas tentang bimbingan dan konseling. Bimbingan dan konseling adalah pelayanan bantuan untuk peserta dididk, baik secara perorangan maupun kelompok agar mandiri dan bisa -berkembang secara optimal, dalam bimbingan pribadi, sosial, belajar maupun karier melalui berbagai jenis layanan dan kegiatan pendukung berdasarkan norma-norma yang berlaku. ${ }^{2}$ Layanan bimbingan dan konseling diharapkan membantu peserta didik dalam pengenalan diri, pengenalan lingkungan dan pengambilan keputusan, serta memberikan arahan terhadap peserta didik, tidak hanya untuk peserta didik yang bermasalah tetapi untuk seluruh peserta didik. Layanan bimbingan dan konseling tidak terbatas pada peserta didik tertentu, melainkan untuk seluruh peserta didik.

\section{PEMBAHASAN}

\section{A. TEORI}

Bimbingan dan konseling memiliki berbagai fungsi diantaranya; pencegahan, pemahaman, penyaluran. Fungsi Konseling disekolah adalah sebagai matra yang ekslusif. ${ }^{3}{ }^{34}$ yang bertujuan supanya orang yang dilayani menjadi mampu mengatur hidupnya sendiri. Dan individu dapat berkembang secara optimal sesuai lingkungannya dan untuk mencapai tujuan konseling diperlukan berbagai pendekatan serta media atau alat pemberian bimbingan. Diantara pendekatan itu adalah dasar konseling yang baik. Menurut Wolman(1973). Pendekatan adalah suatu sistem yang terdidri dari data empiris yang dapat diobservasi/experimentasi dan interpetasinya. Menurut Hansen, stevic dan Warner (1986) pendekatan adalah suatu model tentatif, atas dasar itu dikembangkan berbagai macam rencana dan tindakan. Sedangkan sasaran bimbingan dan konseling secara umum dapat mengembangkan apa yang terdapat pada diri tiap-tiap individu secara optimal. Sedangakan sasaran dan

\footnotetext{
${ }^{-1}$ Sainuddin, I. H., S. (2020, July 27). Dakwah di Era Sosial Media.https://doi.org/10.31219/osf.io/2jxny

2 Prasetiawan, Hardi. "Peran Bimbingan dan Konseling dalam Pendidikan Ramah Anak terhadap Pembentukan Karakter Sejak Usia Dini." Jurnal CARE (Children Advisory Research and Education) 4, no. 1 (2016): 50-60

${ }^{3}$ Bukhori, B. (2014). Dakwah Melalui Bimbingan dan Konseling Islam. Jurnal Konseling Religi, 5(1), 1-18
} 
konseling disekolah dan madrasah adalah tiap-tiap siswa secara perseorangan, dalam arti mengembangkan apa yang ada pada diri tiap-tiap individu (siswa), secara optimalnya agar masing-masing dapat berguna bagi dirinya, lingkungan, masyarakat pada umumnya menurut Hackney dan Cormier (2001) lebih baik ada sasaran yang spasifik, dibandingkan tidak ada sasaran sama sekali.

\section{B. KEBIJAKAN}

Kebijakan tentang fungsi konseling, yang menunjukkan agar setiap individu selalu mendidik diri atau orang lain. Dengan kata lain kearah mana orang itu menjadi baik atau buruk. Yang dikutuip dari surah Al-ashar 1-3. ${ }^{45}$ dan dikutip dari peraturan mentri pendidikan dan kebudayaan pasal 2, tentang fungsi konselor. Kebijakan-kebijakan lain yang dikutip oleh Prayeto. Yamg terdapat pada PP.No.28 dan No 29 Tahun 1990. Dan PP.No.72 Tahun 1991. Dan pada Undang-Undang Sistem Pendidikan Nasional (UUSPN). Tahun 2003 (UU.No.20/2003) Tentang tujuan dari konseling dan diambil dari peraturan mentri pendidikan nasional No 22 tahun 2006 tentang standar isi untuk satuan pendidikan dasar dan menengah yang mencakup fungsi, tujuan, pendekatan dan sarana konseling.

\section{FAKTA}

Permasalahan konseler dan klien, yang disebabkan oleh kebosanan banyak halnya yang timbul karena kebosanan seperti konselor mengambil jarak dari kliennya, makin lama makin menjauh. ${ }^{5}$ klien dapat merasakan rasa aman dan rasa diterima yang sangat penting untuk keberhasilan konseling. Tetapi seperti halnya tingkah laku lainnya yang terus berulang konseling dapat membosankan. Fakta permasalahan menurut Sofya.S, Wills, yang terjadi sering terjadi disekolahan seperti; Mombolos, berpacaran, kecanduan alcohol, narkotika, siswi hamil, berkelahi, dan lain sebagainya.

\section{SOLUSI}

Yang dapat diambil adalah

1. Menganjurkan untuk mengetahui terlebih dahulu dimna letak masalanya. Atau konselor yang bosan, ai harus mengambil tindakan yang tepat, sehinggah tidak merasa terabaikan. Kalau klien yang membosankan, juga supanya konselor membibicarakan kepada klien. ${ }^{6}$

\footnotetext{
${ }^{4}$ Yanto, M., \& Fathurrochman, I. (2019). Manajemen kebijakan kepala madrasah dalam meningkatkan mutu pendidikan. Jurnal konseling Dan Pendidikan, 7(3),123-130.

${ }^{5}$ Yuhana, A. N., \& Aminy, F. A. (2019). Optimalisasi peran guru pendidikan agama Islam sebagai konselor dalam mengatasi masalah belajar siswa. Jurnal Penelitian Pendidikan Islam,[SL], 7(1), 79-96.

${ }^{6}$ Zaini, A. (2015). Membentuk keluarga sakinah melalui Bimbingan dan Konseling Pernikahan. Bimbingan Konseling Islam, 6(1), 89-106.
} 
2. Selain guru BK siswa juga diharuskan untuk memahamkan makna tauhid dan dua kalimat syahadat untuk melakukan pendekatan disiplin merujuk aturan dan tata tertib yang berlaku disekolah beserta sanksinya. ${ }^{7}$

\section{PENUTUP}

1. Bimbingan dan konseling adalah suatu bantuan yang diberikan oleh konselor kepada konseli agar konseli mampu menyelesaikan masalah yang dihadapinya dan juga mampu mengembangkan potensi yang dimilikinya.

2. Bimbingan konseling memiliki berbagai fungsi diantaranya; pencegahan, pemahaman, penyaluran, dan fungsi konseling diskolah adalah sebagai matra yang ekslusif yang bertujuan supanya orang yang dilayani menjadi mampu mengatur hidupnya sendiri.

3. Kebijakan tentang fungsi konseling, yamg menunjukkan agar setiap individu selalu mendidik diri atau orang lain.

4. Permasalan konselor dan klien, yang disebabkan oleh kebosanan banyak halnya yang timbul karena kebosanan seperti konselor mengambil jarak dari kliennya, makin lama makin menjauh. Klien dapat merasakan hal ini, ia akan merasakan rasa aman dan rasa diterima yang sangat penting untuk keberhasilan konseling tetapi seperti halnya tingkah laku lain yang terus berulang konseling dapat membosankan.

\footnotetext{
${ }^{7}$ Sainuddin, Ibnu H., S, Muhammad Arsyam, and Andi M. S. Alwi. 2020. "Pemahaman Makna Tauhid Dan Dua Kalimat Syahadat." OSF Preprints. August 19. doi:10.31219/osf.io/g84vu.
} 


\section{DAFTAR PUSTAKA}

Bukhori, B. (2014). Dakwah Melalui Bimbingan dan Konseling Islam . Jurnal Konseling Religi, 5(1), 1-18.

Prasetiawan, Hardi. "Peran Bimbingan dan Konseling dalam Pendidikan Ramah Anak terhadap Pembentukan Karakter Sejak Usia Dini." Jurnal CARE (Children Advisory Research and Education) 4, no. 1 (2016): 50-60.

Sainuddin, I. H., S. (2020, July 27). Dakwah di Era Sosial Media.https://doi.org/10.31219/osf.io/2jxny

Sainuddin, Ibnu H., S, Muhammad Arsyam, and Andi M. S. Alwi. 2020. "Pemahaman Makna Tauhid Dan Dua Kalimat Syahadat." OSF Preprints. August 19. doi:10.31219/osf.io/g84vu.

Yanto, M., \& Fathurrochman, I. (2019). Manajemen kebijakan kepala madrasah dalam meningkatkan mutu pendidikan. Jurnal Konseling Dan Pendidikan, 7(3), 123130.

Yuhana, A. N., \& Aminy, F. A. (2019). Optimalisasi peran guru pendidikan agama Islam sebagai konselor dalam mengatasi masalah belajar siswa. Jurnal Penelitian Pendidikan Islam,[SL], 7(1), 79-96.

Zaini, A. (2015). Membentuk keluarga sakinah melalui Bimbingan dan Konseling Pernikahan. Bimbingan Konseling 